\title{
A Smart Curtain System
}

\section{Dong Xie ${ }^{a}$, Youcai Jiang ${ }^{\mathrm{b}}$, Mianhao Chen ${ }^{\mathrm{c}}$}

Information School, Hunan University of Humanities, Science and Technology, Loudi, China

adong.xie@hotmail.com, 755721338@qq,com , c287566288@qq.com

\begin{abstract}
This design makes a kind of intelligent curtain system. It realizes intelligent control switch curtain and control air conditioning indoor temperature and humidity. The system consists of mechanical part and control system. The mechanical part includes stepping motor, curtain, etc. The control part consists of the microcontroller minimum system, the sensor and the dc motor drive circuit. The system is controlled by STM32F103ZET6 single chip microcontroller, which can be uploaded to the cloud server via WiFi connection and controlled by smart terminal mobile phone, and can also control the curtain switch with indoor speech implementation. The system has the advantages of simple structure, low production cost, high control accuracy and strong anti-interference ability.
\end{abstract}

Keywords: WiFi, Temperature And Humidity, Single Chip Microcomputer, Intelligent Terminal

\section{Introduction}

New times give people new pursuits. People in the past sought cheap and durable, and now people are more apt to be smart and practical. Many designers prefer to recreate them on existing items to get more powerful and practical items. The design hopes to create more attractive and more humanized smart curtains by innovating on the curtain[1].

\section{Functional Design And Circuit Diagram}

The system consists of mechanical part (step motor, curtain) and control system (single chip minimum system, sensor and dc motor drive circuit). It USES the STM32F103ZET6 microcontroller as the control core, and USES the WiFi connection network to upload to the cloud server, through the intelligent terminal cell phone, the indoor speech implementation controls the curtain switch.

The functional design framework of this system is shown in Fig. 1.

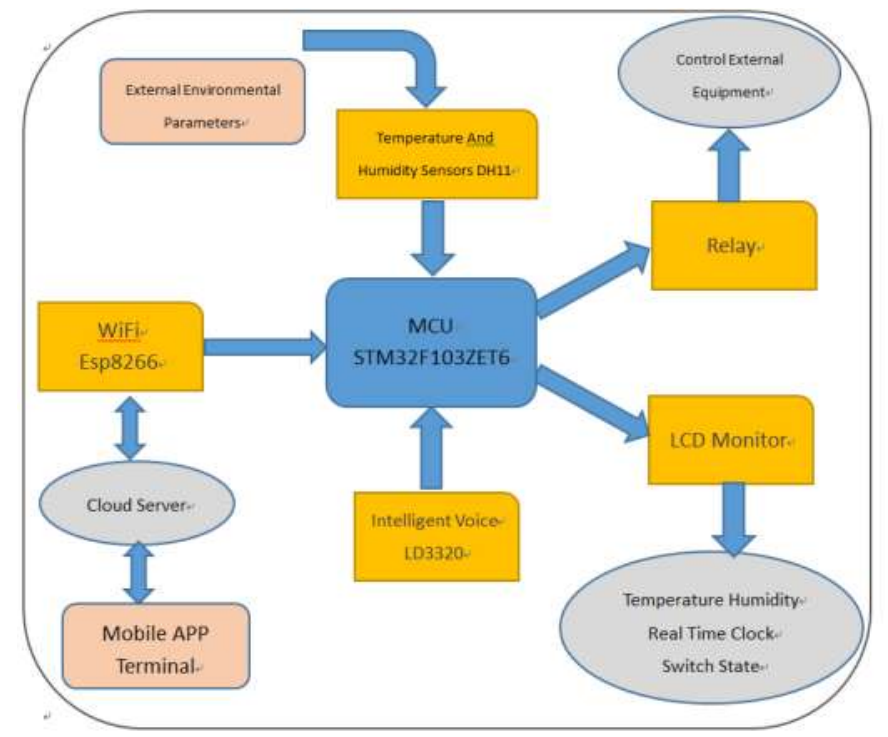

Fig. 1 Functional Design Block Diagram 
The circuit diagram of this system is shown in Fig. 2.

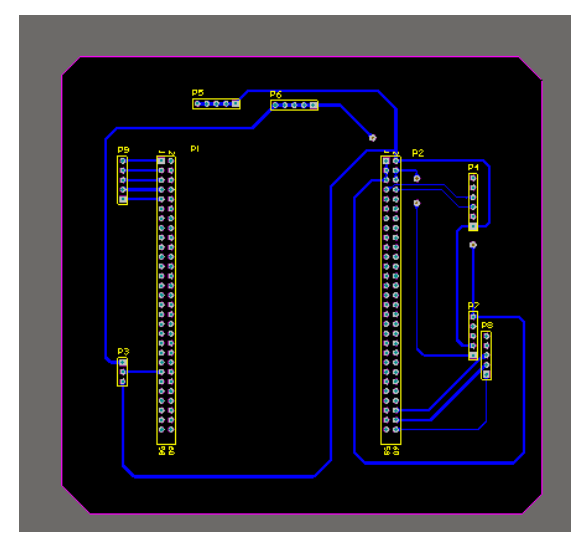

Fig. 2 Circuit Diagram

\section{System Function Analysis}

\section{Intelligent Voice Function Module}

(1) LD3320 is a speech recognition/audio control chip based on Speaker-Independent Automatic Speech Recognition[2]. It provides a real single-chip voice recognition solution.

(2) The LD3320 chip is A high-precision $A / D$ and D/A interface that no longer requires external Flash and RAM. Speech recognition/voice control/man-machine dialogue can be implemented[3]. Also, the list of key words identified can be dynamically edited.

(3) Based on LD3320, it can easily realize speech recognition/audio control/man-machine dialogue function in any electronic product, even simple 51 as the main control chip system[4]. Add the Voice User Interface for all electronic products to the Voice User Interface[5].

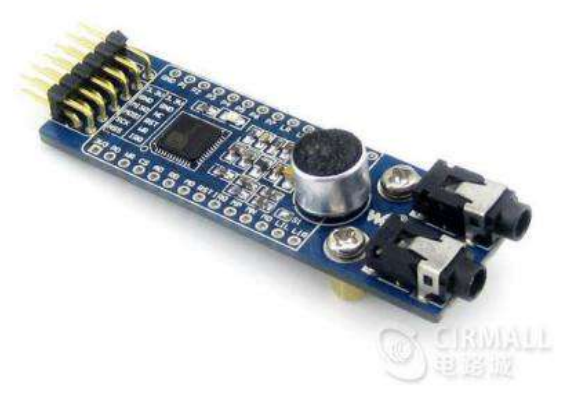

Fig. 3 Intelligent Speech Module

\section{Temperature And Humidity Sensor Module}

DHT11 digital temperature and humidity sensor is a temperature and humidity composite sensor with the output of calibrated digital signals. It applies special digital module acquisition technology and temperature and humidity sensing technology. This ensures high reliability and excellent long-term stability. It has the advantages of low cost, fast response and strong anti-interference ability. Moreover, it has the advantages of super-long signal transmission distance, digital signal output and accurate calibration. The sensor includes a resistive sensing element and an NTC temperature measuring element, which is connected to a high-performance 8-bit single-chip microcomputer. 


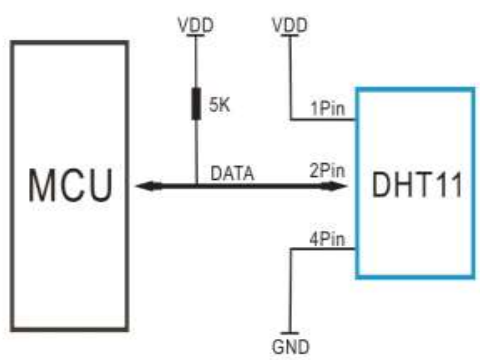

Fig. 4. Temperature And Humidity Sensor Circuit Diagram

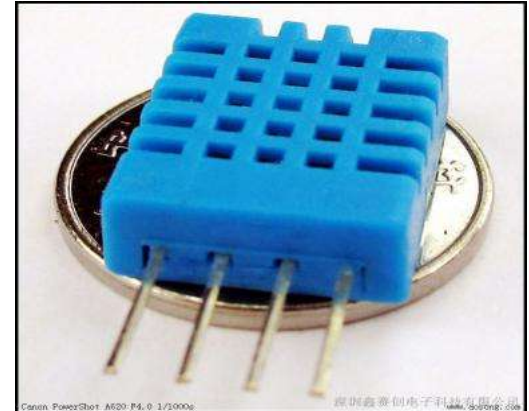

Fig. 5. Physical Image Of Temperature And Humidity Sensor

\section{WiFi Esp8266 Function Module}

(1) ESP8266 is a complete and self-contained WiFi network solution that can run independently and can run as slave on other Host hosts.

(2) ESP8266 can be activated directly from external flash memory when it is equipped with an application and is the only application processor in the device. The built-in cache is good for improving system performance and reducing memory requirements.

(3) ESP8266 dimensions are $5 \times 5 \mathrm{~mm}$. The peripheral components needed for the ESP8266 module include: 10 resistive capacitance inductors, 1 passive vibration, 1 flash. Operating temperature range: $-40 \sim 125{ }^{\circ} \mathrm{C}$.

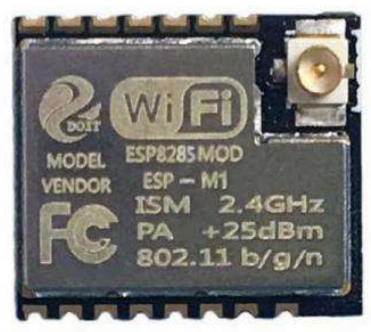

Fig. 6 WiFi Esp8266 Module

\section{Test Results And Analysis}

Our test results were tested on voice control, touch screen control, and WiFi control. The test results showed that the instructions of speech control test were performed normally except for the third test. The instruction response time is within $3 \mathrm{~s}$, within acceptable limits. Touch screen control and WiFi control test are normal; The instruction response time is within $3 \mathrm{~s}$ and within acceptable limits. The results of sound control, touch screen control and WiFi control test are shown below.

Table 1 Voice Control Test Table

\begin{tabular}{|c|c|c|}
\hline The Test Number & Instruction Execution result & Instruction Response Time $(\mathrm{s})$ \\
\hline 1 & Perform Normal & 2.3 \\
\hline 2 & Perform Normal & 3.1 \\
\hline 3 & No Response & 2 \\
\hline 4 & Perform Normal & 2.5 \\
\hline 5 & Perform Normal & 2.7 \\
\hline
\end{tabular}


Table 2 Touch Screen Control Test Table

\begin{tabular}{|c|c|c|}
\hline The Test Number & Instruction Execution result & Instruction Response Time (s) \\
\hline 1 & Perform Normal & 1.2 \\
\hline 2 & Perform Normal & 1.7 \\
\hline 3 & Perform Normal & 1.5 \\
\hline 4 & Perform Normal & 2.1 \\
\hline 5 & Perform Normal & \\
\hline
\end{tabular}

Table $3 \mathrm{WiFi}$ Control Test Table

\begin{tabular}{|c|c|c|}
\hline The Test Number & Instruction Execution result & Instruction Response Time $(\mathrm{s})$ \\
\hline 1 & Perform Normal & 1.7 \\
\hline 2 & Perform Normal & 2.2 \\
\hline 3 & Perform Normal & 1.5 \\
\hline 4 & Perform Normal & 1.8 \\
\hline 5 & Perform Normal & 2.3 \\
\hline
\end{tabular}

\section{Conclusions}

The design and production of the smart curtain system. It realizes intelligent control switch curtain and control air conditioning indoor temperature and humidity. It has the advantages of simple structure, low production cost, high control precision and strong anti-interference ability. The system is mainly composed of mechanical part and control system. The mechanical part includes stepping motor, curtain, etc. The control part consists of the microcontroller minimum system, the sensor and the dc motor drive circuit. The system is controlled by STM32F103ZET6 microcontroller. It USES a WiFi connection to upload to a cloud server; Control the curtain switch through smart terminal cell phone or indoor voice. This is a more attractive, more human smart curtain.

\section{References}

[1] The Internet of Things: A survey[J] . Luigi Atzori,Antonio Iera,Giacomo Morabito. Computer Networks . 2010 (15)

[2] Smart Objects as Building Blocks for the Internet of Things[J] . Kortuem, Gerd,Kawsar, Fahim,Sundramoorthy, Vasughi,Fitton, Daniel. IEEE Internet Computing . 2010 (1)

[3] Embedded Web Server for Wireless Sensor Networks. D. Raskovic,V. Revuri,D. Giessel,A.Milenkovic. 41st Southeastern Symposium on System Theory . 2009

[4] Performance Evaluation of IEEE 802.15.4 LR-WPAN of Industrial Applications. Feng Chen,Nall Wallg,Reinhard Gennall,et al. Wireless on Demand Network Systems and Serviees, WONS 2008 Fifth Annual Confereneeon . 2008

[5] Gator Tech Smart House: A Programmable Pervasive Space. A.Helal, W.Mann, H.Elzabadani, etal. IEEE Computer magazine . 2005 